\title{
Vascular occlusion and infarction in sickle cell crisis and the sickle chest syndrome
}

\author{
NA ATHANASOU, ${ }^{*}$ C HATTON, $\dagger$ J O’ D MCGEE* DJ WEATHERALL $\dagger$ \\ From the University of Oxford, Nuffield Departments of *Pathology and †Clinical Medicine, John Radcliffe \\ Hospital, Oxford
}

SUMMARY A young adult with homozygous sickle cell anaemia (Hb SS) suffered a fatal sickle cell crisis complicated by the sickle chest syndrome. At necropsy multiple large infarcts of the lung, bone marrow, and pituitary gland were found. The large majority of pulmonary infarcts were not associated with either gross or microscopic vaso-occulusion. These findings are discussed and correlated with past and current opinions of sickle cell crisis and the sickle chest syndrome.

Sickle cell crisis refers to any new syndrome that develops rapidly in patients with sickle cell disease on the basis of the inherited abnormality and not due to any other cause.' The term sickle cell crisis is principally a clinical term embracing a number of pathological mechanisms including vaso-occlusion, bone marrow aplasia, and red cell sequestration. In homozygous sickle cell anaemia (Hb SS) painful vaso-occlusive crises are the most common cause of morbidity and mortality in children and adults ${ }^{2}$ and, with the sickle chest syndrome (acute pulmonary involvement without demonstrable bacterial infection), account for more than $90 \%$ of hospital admissions. $^{3}$

Of primary importance in initiating vascular occlusion is the decreased deformability of the sickle erythrocytes themselves. These increase blood viscosity, promoting stasis and augmenting local hypoxia and acidosis, which, in turn, leads to further sickling. Other factors, however, including vascular spasm and the coagulation system are also thought to be involved in the pathogenesis of vasoocclusion. ${ }^{14}$ Infection is believed to be one of the precipitating factors of sickle cell crisis, ${ }^{5}$ but whether the acute chest syndrome is due to infection ${ }^{6}$ or vaso-occlusion ${ }^{7}$ or both is unclear.

We report the clinical and pathological findings of a patient with homozygous sickle cell anaemia who was admitted with symptoms of a painful vasoocclusive crisis and who deteriorated suddenly, showing features of the sickle chest syndrome.

Accepted for publication 14 February 1985

\section{Case report}

A 19 year old woman was admitted complaining of generalised bone pain, which was particularly severe in the chest, back, and limbs. She admitted to having had a cough producing yellow sputum over the preceding two weeks but had no dyspnoea, orthopnoea, or haemoptysis. She had been born to parents of West Indian origin and had been diagnosed as having homozygous sickle cell disease when aged $2^{1 / 2}$ years. During her life she had averaged one or two admissions a year for painful crises, two of which were associated with diffuse lung infiltrates on chest radiograph. When she was 17 years old she had a hepatic sequestration crisis.

On examination, she was obviously in severe pain and feverish $\left(38.2^{\circ} \mathrm{C}\right)$; her pulse rate was 110 beats/min sinus rhythm, jugular venous pressure was not raised, and blood pressure was $130 / 90 \mathrm{~mm} \mathrm{Hg}$. There was no obvious jaundice, cyanosis, or oedema; she had a systolic murmur heard at the left sternal edge and a loud pulmonary second sound. Chest examination was unremarkable. The liver was palpable two finger breadths below the right costal margin. Central and peripheral nervous system were normal. Results of investigations on admission were as follows: haemoglobin concentration $7.2 \mathrm{~g} / \mathrm{dl}$; white cell count $15 \times 10^{4} / \mathrm{l}$; platelet count $582 \times$ $10^{4} / 1$; reticulocyte count $13.2 \%$; coagulation screen normal; total bilirubin $31 \mathrm{mmol} / \mathrm{l}$; aspartate transaminase $96 \mathrm{IU} / \mathrm{l} ; \gamma$-glutamyl transaminase $8 \mathrm{IU} / \mathrm{l}$; alkaline phosphatase $271 \mathrm{IU} / \mathrm{l}$. An electrocardiogram showed sinus tachycardia; chest radiograph showed a mildly enlarged heart with clear lung fields. Blood and sputum cultures taken on admis- 


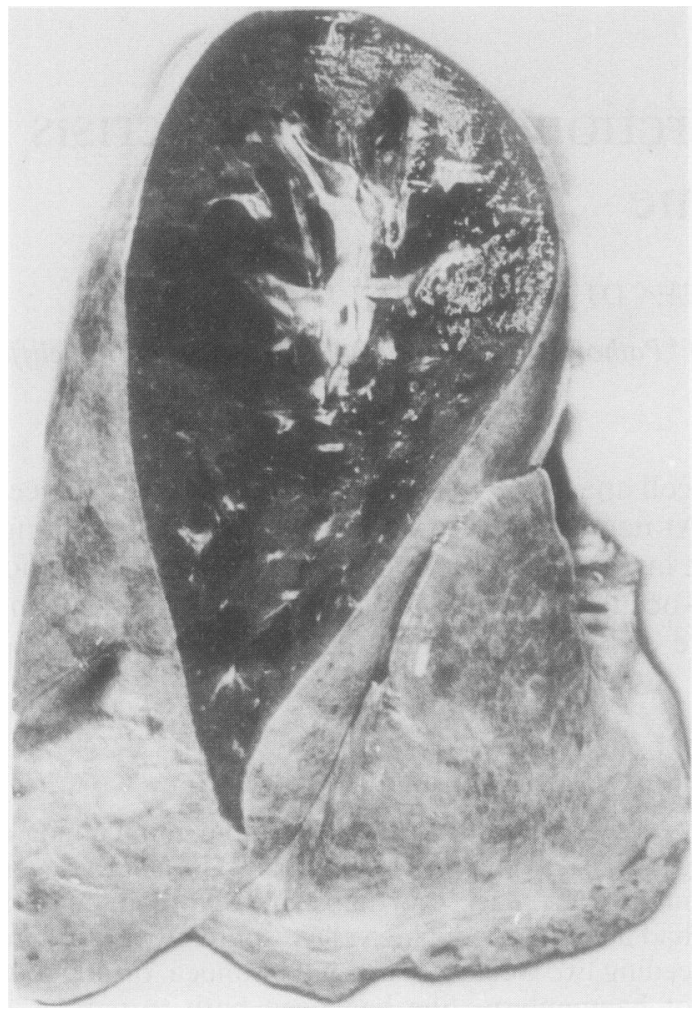

Fig. 1 Multiple lung infarcts. Irregular dark haemorrhagic areas are seen on both the cut and pleural surfaces. No thrombus is seen in the major pulmonary vessels.

sion and during her stay in hospital were sterile and showed no appreciable growth. Pneumococcal antigens were not detected.

On admission she was given pethidine, intravenous hydration, and antibiotics (erythromycin
$250 \mathrm{mg}$ three times daily and ampicillin $500 \mathrm{mg}$ intravenously four times daily). The following day the fever had not settled and she continued to require intravenous pethidine, $75 \mathrm{mg}$ every $2 \mathrm{~h}$. Her blood count showed the following: haemoglobin concentration $6.7 \mathrm{~g} / \mathrm{dl}$; white cell count $23 \times 10^{9} / \mathrm{l}$; platelet count $376 \times 10^{9} / 1$; and reticulocyte count $8.8 \%$. Twenty four hours later she became more breathless. She was feverish with a temperature of $39 \cdot 8^{\circ} \mathrm{C}$. Chest radiograph showed widespread opacities. Oxygen was given in response to her deteriorating clinical condition. Her haemoglobin concentration was $4.9 \mathrm{~g} / \mathrm{dl}$ and her white cell count $28 \times 10^{9} / 1$. She had a sudden cardiac arrest, from which she was promptly resuscitated. Despite continuing resuscitative measures, including blood transfusion, inotropic support, and mechanical ventilation, her condition deteriorated and she died two days later.

\section{NECROPSY FINDINGS}

The body was that of a young, well nourished Negro woman. No skin ulcers, skeletal, or other obvious external abnormalities were noted. The lungs showed the most striking gross changes (Fig. 1). They were heavy (555 $\mathrm{g}$ and $545 \mathrm{~g}$ ) and firm, and there were multiple irregular haemorrhagic areas scattered throughout the parenchyma of both lungs. These ranged from $0 \cdot 5-4 \cdot 5 \mathrm{~cm}$ maximum dimension and a few extended to the pleural surface. Examination of the pulmonary vessels of both lungs showed no large thrombi in the pulmonary trunk, main pulmonary arteries, or immediate lobar branches. Thromboemboli, which were firm, granular, and friable, were present in four small conducting arteries $(0.5-0.7 \mathrm{~cm}$ external diameter), two in each lung. These thromboemboli corresponded to the darker areas, but the rest of the dark areas were not related

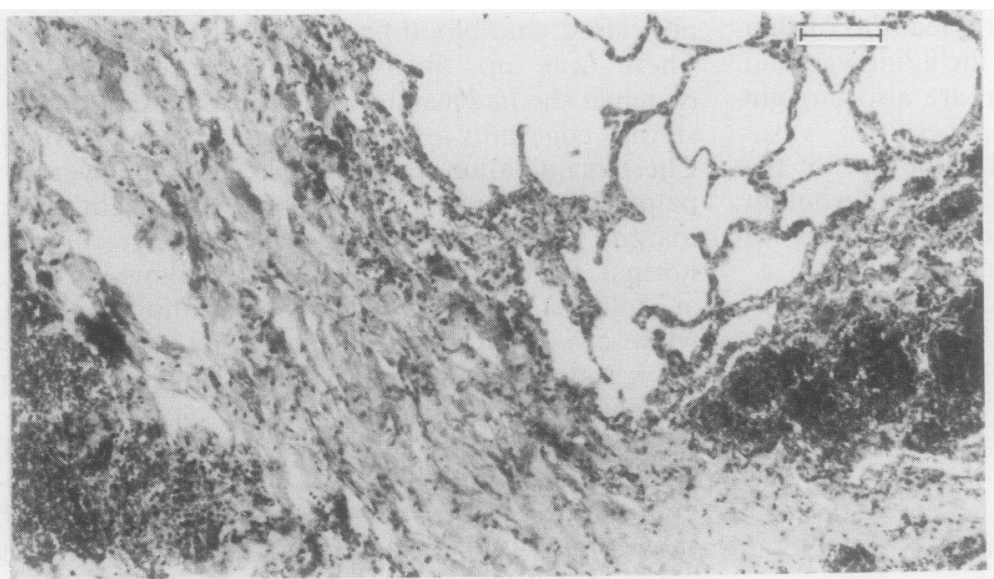

Fig. 2 Two small discrete haemorrhagic pulmonary infarcts near the hilum of the lung separated by an area of uninfarcted lung. Bar $=100 \mathrm{\mu m}$. 


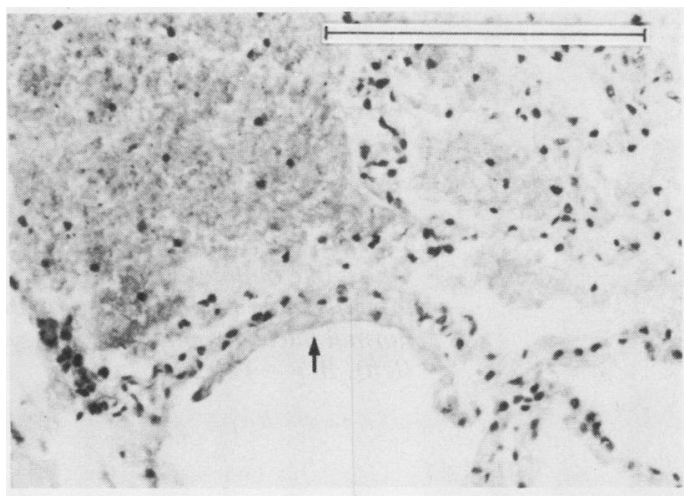

Fig. 3 Margin of small pulmonary infarct (top). Alveoli are filled with blood and there is necrosis of interalveolar septa. At the margin with uninfarcted lung, one of the alveoli shows hyaline membrane formation (arrow). Bar = $100 \mathrm{um}$.

to grossly thrombosed vessels. The pulmonary veins were normal. The heart showed left ventricular hypertrophy (ventricular weight with septum $229 \mathrm{~g}$ ); the right ventricle weighed $52 \mathrm{~g}$. The myocardium appeared normal and the major coronary vessels were all widely patent. No thrombi and little evidence of atheroma was seen in the aorta or other arteries examined. No deep vein thrombosis was noted in the femoral or calf veins and both the portal and systemic venous circulation appeared normal. The spleen $(22 \mathrm{~g})$ was small $(2 \times 1.7 \times$ $1.2 \mathrm{~cm})$, dark, and firm; there were no enlarged

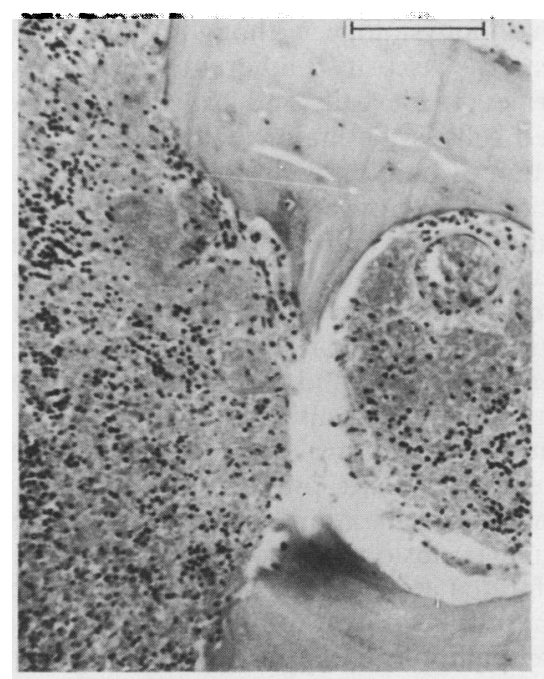

Fig. 4 Bone marrow infarction. Amorphous, eosinophilic cell outlines and nuclear debris fill the medullary cavities. The thin walled blood vessels in this field are dilated and congested but not occluded. Bar $=100 \mu \mathrm{m}$. lymph nodes. The stomach and small and large intestine appeared congested. The liver (1937 g) also appeared congested and firm. The gall bladder and biliary tree looked normal and there were no gallstones. Both kidneys were of normal size and showed old capsular infarcts. The cortex was widened and prominent and, like the medulla, appeared congested. The brain showed flattened gyri and narrow sulci. The cut surface showed numerous dilated small and large blood vessels but no obvious infarction. The pituitary gland appeared normal. There was extension of the red marrow down the femoral shaft and old bony infarcts were noted in the head and shaft of the femur, several of the vertebrae, and the sternum.

\section{HISTOLOGICAL EXAMINATION}

Numerous recent haemorrhagic pulmonary infarcts corresponded to the dark areas seen on macroscopic examination (Figs. 2 and 3). There was intense arteriolar and capillary congestion; the alveoli were filled with blood and there was necrosis of interalveolar septa. There was a striking absence of identifiable thrombosis given the extent of pulmonary infarction. No old, organised thrombi or scars from previous episodes of pulmonary infarction were noted and there was no evidence of pulmonary hypertension. No fat or bone marrow emboli were present. Hyaline membrane formation was seen in alveoli, alveolar duct, and respiratory bronchioles of uninfarcted lung and was presumably related to mechanical ventilation and oxygen treatment received after her cardiac arrest. The heart showed

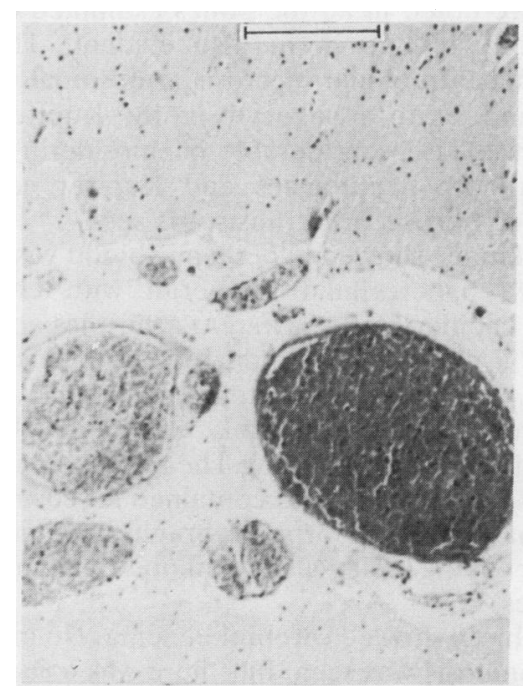

Fig. 5 Dilated, congested but not occluded small and large cerebral vessels filled with sickle cells. This was a common vascular finding in all organs examined. Bar $=100 \mu \mathrm{m}$. 
oedema and myocardial hypertrophy: there were a few haemosiderin granules within myocardial fibres. No infarcts were noted. A single small artery appeared occluded, but other small and large vessels examined were patent, although dilated and filled with red cells.

The spleen was of the small siderofibrotic type with fibrosis of the splenic pulp, which also contained abundant dark brown pigment, mostly iron with a small amount of calcium. The bone marrow appeared hyperplastic with a predominance of red cell precursors. Recent marrow infarction associated with dilated, engorged but not occluded small vessels were noted in all the bones examined (Fig. 4). Old bony infarcts were also evident. The liver showed centrilobular necrosis, sinusoidal congestion, and erythrophagocytosis by Kupffer cells. There was also considerable haemosiderin deposition in both hepatocytes and Kupffer cells. No increased fibrosis or cirrhosis was seen.

The kidney showed hyperaemic blood vessels and enlarged hypercellular glomeruli with engorged, dilated capillary tufts. Afferent arterioles and interlobular arteries were also dilated and intensely congested. There were scattered, isolated sclerosed glomeruli, and individual enlarged glomeruli showed capsular thickening. The proximal and distal tubules were dilated and contained an eosinophilic, proteinaceous or amorphous granular exudate. The tubular lining cells also contained haemosiderin granules.

The brain showed cerebral oedema. No infarction or thrombosis was seen, but there was considerable congestion and dilatation of meningeal and cerebral vessels, both large and small (Fig. 5). The anterior pituitary showed large areas of scattered recent nec-
Fig. 6 Anterior pituitary necrosis. Ghost like outlines of cells in infarcted area (right) contrast with normal nucleated pituitary cells (left). Bar $=100 \mu \mathrm{m}$. rosis (Fig. 6). The remaining organs contained dilated vessels filled with red cells but were otherwise histologically unremarkable.

\section{Discussion}

Vaso-occlusive crises are a common and potentially fatal complication of sickle cell disease. They are most common in homozygous sickle cell anaemia and may be recurrent and focal-for example, hand-foot syndrome or focal necrosis of individual organs-or, less often, systemic with generalised sickling leading to unexpected death.' In both cases the pathophysiology is thought to be similar. The increased viscosity inherent in deoxygenated deformed sickle cells and oxygenated, irreversibly sickled cells is the major factor responsible for obstruction of blood flow in the microvasculature. ${ }^{8}$ In addition, the elongated rigid sickle erythrocyte is less deformable and flows through capillaries with difficulty. A vicious cycle is set up whereby the above factors promote stasis which, in turn, augments local hypoxia and acidosis and leads to increased sickling and ultimately to microvascular occlusion and ischaemic infarction. ${ }^{y}$

The most striking pathological change in the above case was the presence of multiple scattered recent pulmonary infarcts in both lungs. Microscopic vascular occlusion was not seen and only a handful of infarcted areas were associated with macroscopic thrombi. It is difficult to reconcile this finding to the above pathophysiological scheme; in the lungs it would be expected that gross sickling of unsaturated blood in the pulmonary arteries would precipitate in situ vaso-occlusion followed by the local addition of thrombosis after stasis has developed. Moreover, 
given the history of two similar episodes, the lack of fibrous scarring and the absence of organised vascular occlusions in either small or large vessels was surprising. It would thus appear that extensive ischaemic necrosis can occur in sickle cell anaemia without morphological evidence of thrombosis.

In this case capillary engorgement and dilatation were prominent findings not only in the lungs but in all tissues examined. Capillary engorgement has often been described in necropsy reports and protocols of sickle cell anaemia ${ }^{10^{-14}}$ and is thought to represent capillary stasis. Diggs ${ }^{\prime}$ proposed that aggregations of entangled sickle cells intermingled with platelets, white cells, cellular debris, fibrin, and haemoglobin crystals escape from these dilated capillaries, sinusoids, and venules in various parts of the body and finally lodge in the pulmonary arteries.' Such emboli could produce the multiple infarcts noted, but morphological evidence of emboli in many of the infarcted areas is lacking.

Kimmelstiel $^{15}$ described a case of multiple large infarcts of the kidneys, liver, gall bladder, and the brain without detectable thrombosis in a child with sickle cell anaemia. He also noted capillary engorgement and was stimulated to review the published work; he found surprisingly few conclusive reports of vascular thrombosis in sickle cell disease. He suggested that ischaemia in sickle cell crisis could be initiated by vascular spasm; this may lead directly to ischaemic necrosis or, more commonly, be followed by small vessel dilatation with stasis. The capillaries in this phase would appear engorged and dilated. Finally, local ischaemia of tissue and capillary walls may result in organic damage to the vessel walls, degenerative changes, and thrombosis resulting in superimposed and larger infarction. Diggs ${ }^{1}$ noted that the transient nature of symptoms and signs in sickle cell crisis would support a vasospastic process.

Kimmelstiel's hypothesis could neatly explain the lung findings in our case. Areas of pulmonary infarction unassociated with thrombosis are presumably due to vasospasm, and areas of normal lung containing engorged small vessels represent areas which have remained viable after the vasospastic episode. Where thromboses are seen, these form on the basis of an accompanying increase in blood viscosity and the rheological inefficiency of the sickled cells; local ischaemia of tissue and capillary walls resulting in organic damage to the vessel wall with degenerative changes would also favour thrombus formation.

Acute pulmonary disease is a common and serious consequence of sickle cell disease. ${ }^{26} \mathrm{~A}$ common presentation is that of an acute febrile episode associated with the development of a pulmonary infiltrate on chest radiograph. Patients with sickle cell anaemia are at greatly increased risk of infection with certain bacteria, particularly pneumococcus; but in the acute chest syndrome often no organism is isolated. ${ }^{60-23}$ Margolies $^{20}$ suggested that acute pulmonary changes in sickle cell anaemia are due to multiple infarcts producing a pneumonia like picture. Oppenheimer and Esterley ${ }^{7}$ found thromboemboli in most patients with sickle cell disease and noted that pneumonia did not appear to be greater than that in age matched contols. Several recent combined microbiological and clinical studies favour pulmonary intravascular sickling or pulmonary infarction as the cause of the chest syndrome. ${ }^{21-23}$

Our case showed typical features of the acute chest syndrome. ${ }^{23}$ There was a history of cough and chest pain followed by rapidly developing features of bilateral consolidation. Sputum and blood cultures gave consistently negative results; pneumococcal antigens were not detected; and there was no evidence of chest infection histologically. The clinical and radiological features in this case would thus appear to be accounted for by engorgement of the pulmonary vasculature with sickle cells and pulmonary infarction rather than infection. As discussed earlier, the striking absence of thrombosis to account for the large numerous areas of pulmonary infarction would appear to suggest that intravascular sickling alone, possibly preceded by an episode of vasospasm, can lead to pulmonary infarction. Established thrombosis is not necessary for pulmonary infarction to occur but may result because of the increase in blood viscosity and the rheological inefficiency of sickled cells, which favour vascular stasis.

There are a number of factors which make the lung a favourable site for sickling. The mixed venous oxygen tension in the pulmonary capillary bed is about $40 \mathrm{~mm} \mathrm{Hg}$, normally supporting an oxygen saturation of $70 \%$. Even this physiological degree of venous saturation is compatible with widespread sickling in patients with homozygous sickle cell anaemia, as shown by the fact that about $30-60 \%$ of in vivo sickling occurs on the venous side compared with only $20 \%$ on the arterial side. ${ }^{24}$ Moreover, the lower $\mathrm{pH}$ of venous blood would also favour sickling. ${ }^{25}$ In adults or adolescents with homozygous sickle cell anaemia, gas exchange is often abnormal in clinically stable periods, and the alveolar-arterial $\mathrm{pO}_{2}$ difference is widened mainly because of excessive physiological shunting of blood and an abnormal degree of heterogeneity of ventilation to perfusion ratios in the lung. ${ }^{26}$ Sickle lung syndrome has occasionally been associated with mild upper respiratory tract infections. ${ }^{3}$ This can cause bronchiolar narrowing, which would lead to small zones of hypoventilation and a consequent 
increase in the physiological shunt. The effect of such anoxic alveolar areas would be to preserve the sickle form of the erythrocyte in the pulmonary venous circulation and further decrease the velocity of flow in poorly ventilated alveolar areas. ${ }^{27}$

Massive pituitary necrosis, as occurred in our case, has not previously been described anatomically in sickle cell crisis. It is associated with obstetric and non-obstetric shock and has been reported in patients who were maintained on mechanical ventilators before they died. ${ }^{28}$ Our patient had a cardiac arrest and was maintained on mechanical ventilators for two days before her death, and so care must be taken in attaching too much importance to this finding. It is interesting to note, however, that there is one clinically confirmed case of Sheehan's syndrome developing in a patient with sickle cell haemoglobin $C$ disease ${ }^{2 y}$ and that postpartum pituitary necrosis is thought to arise from severe vasospasm. ${ }^{28}$

We are grateful to Dr MS Dunnill for helpful discussions and to Miss L Watts for typing the manuscript.

\section{References}

' Diggs LW. Sickle cell crisis. Am J Clin Pathol 1965;44:1-19.

${ }^{2}$ Davies SC, Hewitt PE. Sickle cell disease. Br J Hosp Med 1984;31:440-4.

${ }^{3}$ Anionwu E, Walford D, Brozovic M, Kirkwood B. Sickle cell disease in a British urban community. $\mathrm{Br}$ Med J 1981;282: 283-6.

${ }^{4}$ Rickles FR, O'Leary DS. Role of coagulation system in pathophysiology of sickle cell disease. Arch Intern Med 1974;133:635-41.

${ }^{5}$ Barrett-Connor E. Bacterial infection and sickle cell anemia. Medicine 1971;50:97-112.

- Barrett-Connor E. Acute pulmonary disease and sickle cell anemia. Am Rev Resp Dis 1971;104:159-65.

7 Oppenheimer EH, Esterley JR. Pulmonary changes in sickle cell disease. Am Rev Respir Dis 1970;103:858-9.

${ }^{8}$ Chien S, Usami S, Bertles JF. Abnormal rheology of oxygenated blood in sickle cell anemia. J Clin Invest 1970;49:623-34.

${ }^{9}$ Klug PP, Lessin LS, Radice P. Rheological aspects of sickle cell disease. Arch Intern Med 1974;133:577-90.

${ }^{10}$ Sydenstricker VP, Mulherin WA, Houseal RW. Sickle cell anemia: report of two cases in children with necropsy in one case. Am J Dis Child 1923;26:132-54.

"Steinberg B. Sickle cell anemia. Arch Pathol 1929;9:876-97.

12 Diggs LW, Ching RE. The pathology of sickle cell anemia. South Med J 1934;27:839-45.

${ }^{13}$ Hughes JG, Diggs LW, Gillespie CE. The involvement of the nervous system in sickle cell anemia. $J$ Pediatr 1940; 17:166-84.

14 Tomlinson WJ. Abdominal crises in uncomplicated sickle cell anemia. Am J Med Sci 1943;202:722-41.

is Kimmelstiel P. Vascular occlusion and ischemic infarction in sickle cell disease. Am J Med Sci 1948;216:11-19.

${ }^{16}$ Edington GM. The pathology of sickle cell disease in West Africa. Trans R Soc Trop Med Hyg 1955;49:253-67.

${ }^{17}$ Edington GM. The pathology of sickle cell haemoglobin $C$ disease and sickle cell anaemia. J Clin Pathol 1957;10:182-6.

${ }_{18}$ Thorburn MJ. The pathology of sickle cell anaemia in Jamaican adults over 30. Trans R Soc Trop Med Hyg 1969;69:98-111.

${ }^{19}$ Diggs LW. Anatomic lesions in sickle cell disease. In: Abramson IT, Bertles JF, Wethers DL, eds. Sickle cell disease. Diagnosis, management, education and research. St Louis: CV Mosby Co, 1973:230.

${ }^{20}$ Margolies MP. Sickle cell anaemia. Medicine 1951;30:357-443.

${ }^{21}$ Charache S, Scott JC, Charache P. Acute chest syndrome in adults with sickle cell anaemia. Arch Intern Med 1979; 139:67-9.

${ }^{22}$ Young RC, Castro O, Baxter RP, et al. The lung in sickle cell disease: a clinical overview of common vascular, infectious and other problems. J Natl Med Assoc 1981;73:19-26.

${ }^{23}$ Davies SC, Win AA, Luce P, Riordan JF. Acute chest syndrome in sickle cell disease. Lancet $1984 ; \mathrm{i}: 36-8$.

${ }^{24}$ Jensen WN, Rucknager DL, Taylor WJ. In vivo study of the sickle cell phenomenon. J Lab Clin Med 1960;56:854-65.

${ }^{25}$ Finch CA. Pathophysiological aspects of sickle cell anaemia. Am J Med 1972;53:1-6.

${ }^{26}$ Bromberg PA. Pulmonary aspects of sickle cell disease. Arch Intern Med 1974;133:652-8.

${ }^{27}$ Moser KM. Shea JG. The relationship between pulmonary infarction, cor pulmonale and the sickle states. Am J Med 1957; 22: 561-80.

${ }^{28}$ Ezrin C, Kovacs K, Horvath E. Pathology of, the adenohypophysis. In: Bloodworth JMB Jr, ed. Endocrine pathology. Baltimore: Williams and Wilkins, 1982:112.

${ }^{24}$ Adadevoh BK. Haemoglobin sickle cell disease and Sheehan's syndrome. Br J Clin Prac 1968;22:442-3.

Requests for reprints to: Dr N Athanasou, University of Oxford, Nuffield Department of Pathology, John Radcliffe Hospital, Oxford OX3 9DU, England. 